\title{
Cultural and quality-of-life considerations when administering corticosteroids as a therapeutic strategy for African American women living with systemic lupus erythematosus
}

This article was published in the following Dove Press journal:

Patient Preference and Adherence

\author{
Dorcey L Applyrs' \\ Edith MWilliams ${ }^{2}$ \\ Trevor D Faith ${ }^{2}$ \\ Diane L Kamen ${ }^{3}$ \\ Elizabeth Vazques ${ }^{4}$ \\ Janine $M$ Jurkowski ${ }^{5}$ \\ 'School of Health Sciences, \\ Excelsior College, Albany, NY, USA; \\ ${ }^{2}$ Department of Public Health \\ Sciences, Medical University of \\ South Carolina, Charleston, SC, \\ USA; ${ }^{3}$ Division of Rheumatology \\ and Immunology, Medical University \\ of South Carolina, Charleston, SC, \\ USA; ${ }^{4}$ Department of Epidemiology \\ and Biostatistics, State University \\ of New York at Albany, One \\ University Place, Rensselaer, NY, \\ USA; ${ }^{5}$ Department of Health Policy, \\ Management, and Behavior, State \\ University of New York at Albany, One \\ University Place, Rensselaer, NY, USA
}

Correspondence: Edith M Williams Department of Public Health Sciences, Medical University of South Carolina, 135 Cannon Street, Suite CS303D, Charleston, SC 29425, USA

Tel + I 843876 I5 I9

Email wiled@musc.edu
Objective: This study investigated the association among corticosteroids, emotional health, physical health, and work/regular activities of daily living in an ethnically diverse sample of women with systemic lupus erythematosus.

Methods: A secondary analysis of data from the Medical University of South Carolina Lupus Database was conducted between confirmed cases of lupus $(n=224)$ and controls $(n=60)$. The sample comprised 57 Caucasian Americans, 141 Gullah African Americans (a subpopulation of African Americans from the Sea Islands of South Carolina and Georgia), and 86 non-Gullah African Americans.

Results: Emotional health outcomes were better for women with systemic lupus erythematosus compared with controls. High emotional health scores may be influenced by cultural factors such as masking emotion, disease-coping mechanisms, religion, and strong familial and social support. Although a significant association was not detected between emotional health and work/regular activities of daily living, relationships were significant after adjusting for corticosteroid use.

Conclusion: These findings suggest corticosteroid use does influence the strength of the association between emotional health and work/regular activities of daily living.

Keywords: systemic lupus erythematosus, emotional health, physical health, Gullah, corticosteroids, quality of life

\section{Introduction}

Systemic lupus erythematosus (SLE) is a chronic autoimmune condition with significant morbidity and mortality. ${ }^{1}$ Currently, there are more than 250,000 Americans living with SLE. ${ }^{2}$ The disease is more prevalent in women than in men, with a ratio of 9:1. ${ }^{1}$ Moreover, African American women are disproportionately impacted by SLE, with the incidence and prevalence of the disease three to four times higher in African Americans than in Caucasian Americans. ${ }^{1,2}$ The diverse symptoms of SLE can contribute to poor emotional and physical health. ${ }^{3}$ For example, patients experiencing hair loss and scarring skin rashes from SLE may perceive themselves as unattractive, resulting in low self-esteem, isolation, and poor emotional health. Patients often experience measurable physical symptoms such as severe joint pain and fatigue, contributing to limited mobility and exercise tolerance.

In addition to the physical and functional disability attributable to SLE, the corticosteroids very commonly used to treat active SLE, often in high doses for severe disease, are associated with short-term side effects and long-term damage as well as 
early mortality among patients with SLE. In the short term, corticosteroid use has been known to cause elevated mood (also known as steroid euphoria), or conversely, steroid psychosis and associated mental deficiencies. ${ }^{4-8}$ These comorbidities are disproportionately experienced by African American women with SLE and can compromise women's ability to perform work/regular activities of daily living with resultant high healthcare costs for patients, their families, and society. ${ }^{9-13}$ Furthermore, because SLE affects women during their most productive years of life, it causes them and their families to experience increased financial hardship and significantly decreases their ability to accumulate wealth due to the financial burden associated with the disease and its treatment. ${ }^{12-14}$

Emotional health and physical health can affect work and daily activities; however, no study has explored these health-related quality-of-life (HRQoL) factors in relation to corticosteroid use in an ethnically diverse sample of women with SLE.

\section{Materials and methods}

\section{Patients and inclusion criteria}

A secondary analysis of data from the Medical University of South Carolina (MUSC) Lupus Database was conducted to assess the associations among corticosteroid use, emotional and physical health, and work/regular activities of daily living in an ethnically diverse sample. Subjects included in the current study were patients with SLE who were participating in a longitudinal, observational, web-based SLE database at the MUSC. Of the 402 patients enrolled, 224 women with SLE had complete data available for this study. Patients were seen on a regular basis in the MUSC lupus clinics. All patients had American College of Rheumatology (ACR) criteria and disease activity information available, as well as quality-of-life measures obtained in the database questionnaire. All SLE patients met at least four of the 1997 ACR revised classification criteria for SLE. Of the 224 patients with SLE in this study, 167 are African American, and 107 of these are Gullah African American from the Sea Islands of South Carolina and Georgia. Additionally, as part of the associated SLE in Gullah Health study, ${ }^{15} 60$ unrelated gender-matched Gullah controls are enrolled and included in this study. This study was conducted with approval from the MUSC Institutional Review Board (approval no HR15014). All participants provided written informed consent for study participation.

\section{Measures and instruments}

Work/regular activities of daily living were conceptualized as paid work or daily activities that included, but were not limited to, house cleaning, gardening, cooking, laundry, and grocery shopping. Work/regular activities of daily living were measured using two separate scales: one measured the degree to which emotion affected women as they undertook work/regular activities of daily living, and the other measured how physical ailments affected work/regular activities of daily living. Both scales were derived from the SF-36, v2 a generic self-administered instrument designed to measure the impact of disease on quality of life - and is valid and reliable for use on individuals living with SLE. ${ }^{16-18}$ The SF-36 consists of 36 items that have been constructed into eight scales: Physical Functioning (PF), Role-Physical (RP), Bodily Pain (BP), General Health (GH), Vitality (VT), Social Functioning (SF), Role Emotional (RE), and Mental Health (MH). ${ }^{19,20}$ These eight scales are combined into two summary measures: Physical Component Summary and Mental Component Summary. Several studies have used the SF-36 with samples from various racial and ethnic backgrounds including both non-Gullah African American and Gullah African American women with SLE. In these studies, the Cronbach's $\alpha$ exceeded the criterion of $0.70 .^{21-24}$

The role of emotion and its effect on work/regular activities of daily living was measured using a three-item, fivepoint Likert scale with a range from one (all of the time) to five (none of the time) and a score ranging from 0 to 15 points. A high score indicated a positive outcome for work/regular activities of daily living. The effect of physical illness on work/regular activities of daily living was measured using a four-item, five-point Likert scale with a range from one (all of the time) to five (none of the time). Scores range from 0 to 20 points, with a high score indicating a positive outcome for work/regular activities of daily living.

Emotional health was conceptualized as a state of being, in terms of feelings, and an individual's personal outlook on life. Emotional health was measured using a five-item, fivepoint Likert scale with a range from one (all of the time) to five (none of the time) and a score range from 0 to 25 . This scale was taken from the SF-36, v2 Mental Health subscale. Items have a positive connotation (eg, "How much of the time during the past 4 weeks have you felt calm and peaceful?") or a negative connotation (eg, "How much of the time during the past 4 weeks have you felt so down in the dumps that nothing could cheer you up?"). Items with a negative connotation were recoded so that a high composite score indicated good emotional health.

Physical health was conceptualized as the ability to carry out activities that involve muscle strength. Physical health was measured as a categorical variable on a 10-item, threechoice scale which ranged from one (yes, limited a lot) to three 
(no, not limited at all). The score ranged from 0 to 30 . This scale was taken from the SF-36, v2 Physical Functioning subscale. A high composite score indicated good physical health.

Demographic data were collected on selected individual characteristics including, race/ethnicity, age, education, and employment status. Clinical data included corticosteroid use and comorbid medical conditions. Race/ethnicity was measured as a categorical variable by using two items from the subject registration form. Subjects who answered either African American or Caucasian for self-identified race were included and other races were excluded from this analysis due to the small sample size. African American subjects identified as either Gullah or non-Gullah African Americans. For purposes of data analysis, ethnicity was recoded using dummy variables with non-Gullah African Americans used as the referent group.

Corticosteroids use was measured as a continuous variable to establish the mean duration of treatment (in years). However, for purposes of data analysis, corticosteroid use was recorded as a dichotomous variable yes (corticosteroid use) or no (no corticosteroid use). Comorbid medical conditions were ascertained using a past medical history form that listed 16 diseases, including diabetes, stroke, fibromyalgia, and cancer. For data analysis, comorbid medical conditions were measured using a dichotomous variable yes (at least one comorbid medical condition) or no (no comorbid medical condition).

Disease damage caused by SLE was measured by the Systemic Lupus International Collaborating Clinics/ American College of Rheumatology Damage Index (SLICC/ ACR DI) - an indicator of bodily damage from the time of disease diagnosis. Damage has been described as an irreversible change, unrelated to active inflammation, occurring since the onset/diagnosis of lupus, ascertained by clinical assessment and present for at least 6 months, unless otherwise stated. ${ }^{25}$ It is a summary scale that uses 12 categories representative of organ systems: ocular, neuropsychiatric, renal, pulmonary, cardiovascular, peripheral vascular, gastrointestinal, musculoskeletal, skin, premature gonadal failure, diabetes, and malignancy. The summary scores ranged from 0 (no damage) to 46 (maximum damage). ${ }^{25}$

\section{Statistical analyses}

All analyses were conducted using the Statistical Analysis System software, version 9.3. Descriptive analysis was conducted to examine sample characteristics. Bivariate analysis using the chi-square test was conducted to assess associations between the following variables: emotional health versus work/regular activities of daily living (role physical) and physical health versus work/regular activities of daily living (role emotional). The two-sample Student's $t$-test was used for continuous variables to assess unadjusted differences in the means of the summary scores between groups.

Linear regression analyses were conducted to assess associations among corticosteroid use, emotional health, physical health, and work/regular activities of daily living (role physical). The following three regression equations were tested: 1) whether there was an association between emotional health and work/regular activities of daily living (role physical); 2) whether there was an association between physical health and work/regular activities of daily living (role emotional); and 3) whether the association between emotional health and regular activities of daily living (role physical) was exacerbated by corticosteroid use.

To further evaluate significant associations, the TukeyKramer post hoc test was used to determine whether the means of the three ethnic groups differed significantly. Group comparisons among women with SLE using the chi-square test, the one-way analysis of variance, and the Kruskal-Wallis test included the covariates: corticosteroids, education, disability status, age, depression, and hypertension.

\section{Results}

Descriptive statistics on the characteristics of the study sample are presented in Table 1. Patients with SLE were

Table I Characteristics of participants $(\mathrm{N}=284)$

\begin{tabular}{|c|c|c|}
\hline Characteristics & $\begin{array}{l}\text { SLE cases } \\
(n=224)\end{array}$ & $\begin{array}{l}\text { Related controls } \\
(n=60)\end{array}$ \\
\hline Mean age (years) SD & $39 \pm 14$ & $42 \pm 15.4$ \\
\hline \multicolumn{3}{|l|}{ Race/ethnicity } \\
\hline Non-Gullah African American n (\%) & $84(38 \%)$ & $2(3 \%)$ \\
\hline Gullah African American n (\%) & 87 (39\%) & $54(90 \%)$ \\
\hline Caucasian American n (\%) & $53(24 \%)$ & $4(7 \%)$ \\
\hline \multicolumn{3}{|l|}{ Education } \\
\hline Less than high school n (\%) & $2(0.81 \%)$ & $2(3.33 \%)$ \\
\hline High school n (\%) & $76(31 \%)$ & $16(26.67 \%)$ \\
\hline Some college $n(\%)$ & 27 (II\%) & $18(30 \%)$ \\
\hline College $n(\%)$ & $28(11 \%)$ & $9(15 \%)$ \\
\hline Technical college or trade $\mathrm{n}(\%)$ & 37 (I5\%) & $8(13.33 \%)$ \\
\hline Postgraduate $\mathrm{n}(\%)$ & $17(7 \%)$ & $4(6.67 \%)$ \\
\hline \multicolumn{3}{|l|}{ Employment status } \\
\hline Working n (\%) & $82(36 \%)$ & $39(65 \%)$ \\
\hline Retired n (\%) & $15(7 \%)$ & $5(8 \%)$ \\
\hline Homemaker n (\%) & $9(4 \%)$ & $2(3 \%)$ \\
\hline Disabled n (\%) & $62(28 \%)$ & I (2\%) \\
\hline Unemployed n (\%) & $30(13 \%)$ & $9(15 \%)$ \\
\hline Other $\mathrm{n}(\%)$ & $18(8 \%)$ & $5(8 \%)$ \\
\hline \multicolumn{3}{|l|}{ Corticosteroid use } \\
\hline Mean duration years \pm SD & $5.57 \pm 4.83$ & - \\
\hline \multicolumn{3}{|l|}{ SLICC Disease Damage Index } \\
\hline Mean \pm SD & $2.41 \pm 1.7$ & - \\
\hline
\end{tabular}


generally similar in age and education level to subjects in the control group, whereas the groups varied somewhat in race (control group was disproportionately Gullah African American) and employment status (individuals in the control group were more likely to be working and not disabled).

Table 2 shows correlation coefficients of emotional health, physical health, and work with regular activities of daily living (role physical) and work/regular activities of daily living (role emotional), both before and after adjusting for corticosteroid use. Higher emotional health scores were correlated with higher scores for work/regular activities of daily living (role physical; r-estimate $=0.17, p<0.01$ ). After adjusting for corticosteroid use, emotional health remained significantly correlated with work/regular activities of daily living (role physical; r-estimate $=0.40, p<0.01$ ). Similarly, higher physical health scores were correlated with higher scores for work/regular activities of daily living (role emotional; r-estimate $=0.60, p<0.01$ ).

The group comparisons using the Student's $t$-test, and the Wilcoxon rank sum test demonstrated that women with SLE reported higher emotional health scores than controls (18.16 vs $11.08, p<0.01)$. In contrast, women with SLE reported lower scores in the areas of physical health $(22.02$ vs $26.22, p<0.01$ ), work/regular activities of daily living (role physical; 13.40 vs 16.91, $p<0.01$ ) and work/regular activities of daily living (role emotional; 11.58 vs 12.62 , $p<0.05)$ compared with controls.

Table 3 shows the unadjusted linear regression analyses for the association between variables of interest: emotional health, physical health, work/regular activities of daily living (role emotional), and work/regular activities of daily living (role physical). Model 1 demonstrates that higher physical health scores were associated with higher work/ regular activities of daily living (role emotional) scores $(\beta=0.36, p<0.01)$. Model 2 found that emotional health was not significantly associated with work/regular activities

Table 2 Differences in HRQoL scores between women with SLE and controls

\begin{tabular}{|c|c|c|c|}
\hline \multirow[t]{2}{*}{ Characteristics } & \multirow{2}{*}{$\begin{array}{l}\text { SLE cases } \\
(\mathrm{n}=244) \\
\text { Mean } \pm \text { SD }\end{array}$} & \multirow{2}{*}{$\begin{array}{l}\begin{array}{l}\text { Controls } \\
(\mathrm{n}=60)\end{array} \\
\text { Mean } \pm \text { SD }\end{array}$} & \multirow[t]{2}{*}{$p$-value } \\
\hline & & & \\
\hline Emotional health & $18.16 \pm 4.80$ & $11.80 \pm 7.32$ & $<0.0 I^{*}$ \\
\hline Physical health & $22.20 \pm 5.89$ & $26.50 \pm 5.53$ & $<0.0 \mathrm{I}^{\#}$ \\
\hline \multicolumn{4}{|c|}{ Work/regular activities of daily living } \\
\hline Role physical & $13.40 \pm 4.94$ & $16.91 \pm 4.52$ & $<0.0 \mathrm{I}^{\#}$ \\
\hline Role emotional & $11.58 \pm 3.67$ & $12.62 \pm 3.60$ & $0.02^{\#}$ \\
\hline
\end{tabular}

Notes: *Significant difference based on a Student's $t$-test. "Hignificant difference based on Wilcoxon rank sum test.

Abbreviation: SLE, Systemic lupus erythematosus.
Table 3 Linear regression models for the association between emotional health, physical health, and work/regular activities of daily living before and after adjusting for corticosteroid use

\begin{tabular}{|c|c|c|c|c|c|}
\hline \multirow[t]{2}{*}{ Model } & \multirow[t]{2}{*}{ Variables } & \multicolumn{2}{|c|}{$\begin{array}{l}\text { Work/regular } \\
\text { activities of } \\
\text { daily living } \\
\text { (role emotional) }\end{array}$} & \multicolumn{2}{|c|}{$\begin{array}{l}\text { Work/regular } \\
\text { activities of } \\
\text { daily living } \\
\text { (role physical) }\end{array}$} \\
\hline & & $\beta$ & $p$-value & $\bar{\beta}$ & $p$-value \\
\hline I & Physical health & 0.36 & $<0.0 I^{*}$ & - & - \\
\hline 2 & Emotional health & - & - & 0.04 & 0.43 \\
\hline \multirow[t]{2}{*}{3} & Emotional health & - & - & 0.38 & $<0.01 *$ \\
\hline & Corticosteroids & & & -1.80 & 0.51 \\
\hline
\end{tabular}

Notes: Models I and 2: unadjusted; Model 3: adjusted. *Significant difference detected.

of daily living (role physical; $\beta=0.04, p=0.43$ ). Model 3 was restricted to women with SLE only. After adjusting for corticosteroid use, emotional health was significantly associated with work/regular activities of daily living (role physical; $\beta=0.38, p<0.01$ ).

As shown in Table 4, racial and ethnic differences were observed for emotional health $(p<0.004)$ and work/regular activities of daily living (role physical) scores $(p<0.04)$. Significant ethnic differences in mental health were observed between both non-Gullah African Americans and Caucasian American women with SLE and the Gullah African American and Caucasian American women with SLE (post hoc $p=0.004)$. Overall, non-Gullah African Americans reported similar emotional health scores compared to Gullah African Americans and lower scores when compared to Caucasian American women with SLE (17.46; 17.70 vs 20.10). For work/regular activities of daily living (role physical), significant ethnic differences were observed between non-Gullah African American and Caucasian American women with SLE (post hoc $p<0.03$ ). Non-Gullah African Americans had lower scores in work/regular activities of daily living (role physical) compared to Caucasian American women with SLE (12.74 vs 14.94).

Table 5 shows unadjusted and adjusted linear regression analyses for emotional health and work/regular activities of daily living (role physical). Race/ethnicity acted as a moderator between emotional health and work/regular activities of daily living (role physical; $p<0.01$ ), and the association between emotional health and work/regular activities of daily living remained significant $(\beta=0.37, p<0.01)$. After adjusting for ethnicity, education, age, disability status, stroke, dialysis, and depression, the association between emotional health and work/regular activities of daily living (role physical) remained significant but was decreased $(\beta=0.23, p<0.01)$. 
Table 4 Ethnic differences in HRQoL scores among women with SLE

\begin{tabular}{|c|c|c|c|c|}
\hline \multirow[t]{2}{*}{ Characteristics } & $\begin{array}{l}\text { Non-Gullah African } \\
\text { Americans }(n=79)\end{array}$ & $\begin{array}{l}\text { Gullah African } \\
\text { Americans }(n=83)\end{array}$ & $\begin{array}{l}\text { Caucasian } \\
\text { Americans }(n=50)\end{array}$ & \multirow[t]{2}{*}{$p$-value } \\
\hline & Mean \pm SD & Mean \pm SD & Mean \pm SD & \\
\hline Emotional health & $17.46 \pm 4.70$ & $17.70 \pm 5.18$ & $20.10 \pm 3.80$ & $0.004^{*}$ \\
\hline \multicolumn{5}{|c|}{ Work/regular activities of daily living } \\
\hline Role physical & $12.74 \pm 5.03$ & $13.52 \pm 4.65$ & $14.94 \pm 4.84$ & $0.04 *$ \\
\hline
\end{tabular}

Notes: *Significant differences were observed for non-Gullah African Americans and Caucasian American women and Gullah African Americans and Caucasian American women with SLE (post hoc $p<0.05$ ).

Abbreviation: SLE, Systemic lupus erythematosus.

\section{Discussion}

This study explored the relationships among variables related to everyday life for women with SLE. Our results indicate that physical health has a significantly greater association with decreased work/regular activities of daily living compared with emotional health. Additionally, significant ethnic differences exist in the association between emotional health and work/regular activities of daily living among women with SLE. Among the women with SLE in our study, nonGullah African Americans had similar emotional health scores compared with Gullah African Americans and lower scores compared with Caucasian Americans. However, non-Gullah African American women with SLE had lower scores for work/regular activities of daily living compared with Gullah African American and Caucasian American women with SLE. Emotional health outcomes were better

Table 5 Linear regression models for the association between emotional health, physical health, and work/regular activities of daily living before and after adjusting for corticosteroid use

\begin{tabular}{|c|c|c|c|}
\hline \multirow[t]{3}{*}{ Models } & \multicolumn{3}{|c|}{ Work/regular activities of daily living } \\
\hline & \multicolumn{3}{|l|}{ Role physical } \\
\hline & Variables & $\beta$ & $p$-value \\
\hline I & Emotional health & 0.40 & $<0.01 *$ \\
\hline \multirow[t]{3}{*}{2} & Emotional health & 0.40 & $<0.01 *$ \\
\hline & Caucasian American & 1.46 & 0.09 \\
\hline & Gullah African American & 1.13 & 0.12 \\
\hline \multirow[t]{4}{*}{3} & Emotional health & 0.37 & $<0.01 *$ \\
\hline & Caucasian American & 1.24 & 0.19 \\
\hline & Gullah African American & 1.39 & 0.12 \\
\hline & Corticosteroid use & 0.07 & 0.38 \\
\hline \multirow[t]{9}{*}{4} & Emotional health & 0.23 & $<0.01 *$ \\
\hline & Caucasian American & 0.13 & 0.26 \\
\hline & Gullah African American & 1.66 & $0.03 *$ \\
\hline & Education & 0.72 & 0.29 \\
\hline & Age & -0.04 & $0.05^{*}$ \\
\hline & Disability status & -3.21 & $<0.01 *$ \\
\hline & Stroke & -0.60 & 0.43 \\
\hline & Dialysis & 1.33 & -0.26 \\
\hline & Depression & -1.77 & $0.02 *$ \\
\hline
\end{tabular}

Notes: Model I: unadjusted; Models 2-4: adjusted. *Significant difference was observed. for women with SLE overall, when compared with controls; however, it is important to note that these groups varied in their demographic characteristics, which could account for variations in emotional coping styles.

High emotional health scores reported by non-Gullah and Gullah African American women with SLE are novel and contrary to the phenomena that we thought we understood in the SLE scientific literature. The negative effects of SLE on emotional health are well documented. Our findings suggest there may be emotional health protective factors that are culturally unique among this population of African American women with SLE residing in the Sea Island regions of coastal South Carolina. This further justifies examination into the impact of racial and ethnic sociocultural influences on disease status within this population.

Whereas side effects of corticosteroid use could be a confounding factor, psychiatric side effects are generally present in a subsect of the population, thereby reducing their ability to cause significant variation..$^{48}$ Thus, we suspect that the pervasive sociocultural factors influencing this outcome include masking emotion, ${ }^{26}$ disease-coping mechanisms, religion, and strong familial and social support due to the high prevalence of multi-patient families with SLE among the Gullah. ${ }^{16}$ There may be an interplay between these cultural factors and the adoption of a Superwoman role by Gullah African Americans and non-Gullah African Americans who collectively comprised the majority of women with SLE (77\%) in the study sample. The Superwoman role - a survival mechanism adopted by African American women to cope with racism and oppression ${ }^{27}$ - could have manifested in the form of stress-relating coping strategies such as an obligation to manifest strength, an obligation to suppress emotions, and resistance to being vulnerable. African American women, both non-Gullah and Gullah, who adopt the Superwoman role are more likely to engage in emotional suppression, which can lead to detrimental changes in immune functioning, illness, and mortality. ${ }^{27,28}$ Despite the negative impact of certain aspects of the Superwoman role on health outcomes, 
there are positive aspects of this phenomenon; these positive impacts have benefited African American women who have managed historically to demonstrate strength in the face of adversity and tremendous hardship. ${ }^{27}$ The lack of a significant association detected between emotional health and work/ regular activities of daily living (role physical) was consistent with other findings. ${ }^{29}$

This study attempted to extend previous examinations of the association of emotional health and work/regular activities of daily living among cases and controls ${ }^{13,29,30}$ by assessing the moderating effect of corticosteroids - a common treatment in SLE known to cause emotional distress, mood disorders, and psychiatric disorders. ${ }^{4-8,31}$ Despite the welldocumented side effects of corticosteroid use, prior studies assessing the effects of corticosteroids and the associations between SLE and emotional health and work/regular activities of daily living are scarce. ${ }^{3}$ Whereas a significant association was not detected for emotional health and work/regular activities of daily living after adjusting for corticosteroid use, a significant association between emotional health and work/regular activities of daily living (role physical) was detected. These findings suggest that corticosteroid use does influence the strength of the association between emotional health and work/regular activities of daily living; however, it cannot be stated with certainty if this variation is due to the intended treatment effects of the drug or the psychiatric side effects.

This study was limited by the dichotomous coding of corticosteroid use, without accounting for dose, and did not account for the influence of steroid-sparing immunosuppressing medications often used to treat SLE and allowing corticosteroids to be tapered off. From our experience with patients followed in this cohort, a significant proportion of patients continue on corticosteroid therapy for SLE despite trials of other therapies. Our findings will help add support to maximizing steroid-sparing treatments with the goal of tapering off even low doses of corticosteroids. Another notable limitation of this study is the between-group demographic variations; this limits the power of the associations observed; however the current study provides a preliminary and novel inference. Similarly, due to the unique demographic makeup of this population (being largely African American and/or Gullah), the conclusions drawn from the data are not generalizable and should not be applied to other populations.

The finding that racial and ethnic differences were detected for emotional health scores among women with SLE, but not among controls, and that non-Gullah African American women reported poorer emotional health compared to Gullah African Americans and Caucasian American women with SLE are consistent with other research that compared Hispanics from Texas, Hispanics from Puerto Rico, African Americans, and Caucasian Americans $(n=1,351) .{ }^{32}$ According to Alarcón et al, the African American race is associated with poorer emotional health compared with other racial/ ethnic groups. Although there are unique cultural differences between these two groups, significant differences in emotional health may not have been observed due to shared racial and sociocultural experiences, environmental stressors, coping strategies, and disproportionate disease activity and damage. ${ }^{1,26,27}$

This study revealed that physical health had a greater association with work/regular activities of daily living compared with emotional health, which is similar to empirical findings that declines in physical health and work/regular activities of daily living accompany SLE in the broader population. ${ }^{10,33-37}$

Finally, non-Gullah African Americans experienced more deficits in work/regular activities of daily living compared with their Caucasian American counterparts. These findings are consistent with previous research ${ }^{13,14}$ that revealed African Americans were more likely to report work disability.

\section{Conclusion}

Our findings highlight the importance of considering the negative impact of corticosteroids on emotional health among women with SLE - particularly among African American women who disproportionately experience poor health outcomes, yet often require high doses of corticosteroids for treating life-threatening lupus manifestations such as kidney and brain involvement. Although this therapeutic strategy improves physical health, the emotional health implications should not be overlooked. Improvements in SLE outcomes can only be accomplished if racial and ethnic sociocultural factors are examined in research and accounted for in the administering of corticosteroids and the development and implementation of interventions. Despite the diversity that exists within the African American population, cultural differences are not always considered in SLE research and interventions; however, it is known that there are ethnic variations in SLE incidence, prevalence, disease damage, and mortality, and this study assessed ethnic differences. This study provides novel insight into the cultural differences among African Americans, their interplay with 
corticosteroid use, and how these can affect quality-of-life outcomes.

\section{Acknowledgments}

This project was supported by the Rheumatology and Immunology Multidisciplinary Clinical Research Center, National Institutes of Health (NIH)/National Institute of Arthritis and Musculoskeletal and Skin Diseases (NIAMS) Grant (no AR062755). The contents of this article are solely the responsibility of the authors and do not necessarily represent the official views of the NIH or NIAMS. This work's abstract has been presented previously and published in the Annals of the Rheumatic Diseases.

\section{Disclosure}

The authors report no conflicts of interest in this work.

\section{References}

1. Pons-Estel GJ, Alarcón GS, Scofield L, Reinlib L, Cooper GS. Understanding the epidemiology and progression of systemic lupus erythematosus. Semin Arthritis Rheum. 2010;39(4):257-268.

2. Rahman A, Isenberg DA. Systemic lupus erythematosus. N Engl J Med. 2008;358(9):929-939.

3. Gallop K, Nixon A, Swinburn P, Sterling KL, Naegeli AN, Silk ME. Development of a conceptual model of health-related quality of life for systemic lupus erythematosus from the patient's perspective. Lupus. 2012;21(9):934-943.

4. McGrath $\mathrm{P}$, Holewa $\mathrm{H}$. The emotional consequences of corticosteroid use in hematology: preliminary findings. J Psychosoc Oncol. 2010; 28(4):335-350.

5. Chau SY, Mok CC. Factors predictive of corticosteroid psychosis in patients with systemic lupus erythematosus. Neurology. 2003;61(1): 104-107.

6. Kenna HA, Poon AW, de los Angeles CP, Koran LM. Psychiatric complications of treatment with corticosteroids: review with case report. Psychiatry Clin Neurosci. 2011;65(6):549-560.

7. Warrington TP, Bostwick JM. Psychiatric adverse effects of corticosteroids. Mayo Clin Proc. 2006;81(10):1361-1367.

8. Hawro T, Krupińska-Kun M, Rabe-Jabłońska J, et al. Psychiatric disorders in patients with systemic lupus erythematosus: association of anxiety disorder with shorter disease duration. Rheumatol Int. 2011; 31(10):1387-1391.

9. Nass T, Freeman J, Rodgers AN. Lupus: A patient care guide for nurses and other heath professionals. Diance Pub Co: Darby, PA. 2000.

10. Duvdevany I, Cohen M, Minsker-Valtzer A, Lorber M. Psychological correlates of adherence to self-care, disease activity and functioning in persons with systemic lupus erythematosus. Lupus. 2011;20(1):14-22.

11. Kuper BC, Failla S. Shedding new light on lupus. Am J Nurs. 1994; 94(11):26-33; quiz 32-33.

12. Lau CS, Mak A. The socioeconomic burden of SLE. Nat Rev Rheumatol. 2009;5(7):400-404.

13. Baker K, Pope J. Employment and work disability in systemic lupus erythematosus: a systematic review. Rheumatology (Oxford). 2009; 48(3):281-284.

14. Bertoli AM, Fernández M, Alarcón GS, Vilá LM, Reveille JD. Systemic lupus erythematosus in a multiethnic US cohort LUMINA (XLI): factors predictive of self-reported work disability. Ann Rheum Dis. 2007;66(1):12-17.
15. Kamen DL, Barron M, Parker TM, et al. Autoantibody prevalence and lupus characteristics in a unique African American population. Arthritis Rheum. 2008;58(5):1237-1247.

16. Barnado A, Wheless L, Meyer AK, Gilkeson GS, Kamen DL. Quality of life in patients with systemic lupus erythematosus (SLE) compared with related controls within a unique African American population. Lupus. 2012;21(5):563-569.

17. Stoll T, Gordon C, Seifert B, et al. Consistency and validity of patient administered assessment of quality of life by the MOS SF-36; its association with disease activity and damage in patients with systemic lupus erythematosus. J Rheumatol. 1997;24(8):1608-1614.

18. Saba J, Quinet RJ, Davis WE, et al. Inverse correlation of each functional status scale of the SF-36 with degree of disease activity in systemic lupus erythematosus (m-SLAM). Joint Bone Spine. 2002;70(5):348-351.

19. Ware JE, Kosinski M, Dewey JE. How to Score Version 2 of the SF-36 Health Survey. Lincoln: Quality Metric Inc.; 2001.

20. Ware JE Jr. SF-36 health survey update. Spine (Phila Pa 1976). 2012; 25(24):3130-3139.

21. Garratt AM, Ruta DA, Abdalla MI, Buckingham JK, Russell IT. The SF36 health survey questionnaire: an outcome measure suitable for routine use within the NHS. BMJ. 1993;306(6890):1440-1444.

22. Brazier JE, Harper R, Jones NM, et al. Validating the SF-36 health survey questionnaire: new outcome measure for primary care. BMJ. 1992; 305(6846):160-164.

23. Lam CL, Gandek B, Ren XS, Chan MS. Tests of scaling assumptions and construct validity of the Chinese (HK) version of the SF-36 Health Survey. J Clin Epidemiol. 1998;51(11):1139-1147.

24. Peek MK, Ray L, Patel K, Stoebner-May D, Ottenbacher KJ. Reliability and validity of the SF-36 among older Mexican Americans. Gerontologist. 2004;44(3):418-425.

25. Gladman DD, Urowitz MB, Goldsmith CH, et al. The reliability of the systemic lupus international collaborating clinics/American college of rheumatology damage index in patients with systemic lupus erythematosus. Arthritis Rheum. 1997;40(5):809-813.

26. Johnson-Spruill I, Tripp-Reimer T. Exploring heterogeneity within the African-American population: the Gullahs of the South Carolina. $J$ Natl Black Nurses Assoc. 2013;24(2):44-50. Availabel from: https://web-b-ebscohost-com.ezproxy-v.musc.edu/ehost/detail/ detail?vid=4\&sid=084d90c1-3ad8-4f85-907d-f682e9e3e1d7\%40pdcv-sessmgr01\&bdata=JnNpdGU9ZWhvc3QtbGl2ZQ\%3d\%3d\#AN=10 $7892208 \& \mathrm{db}=\mathrm{ccm}$. Accessed November 02, 2017.

27. Woods-Giscombé CL. Superwoman schema: African American women's views on stress, strength and health. Qual Health Res. 2010;20(5):668-683.

28. Woods-Giscombé CL, Black AR. Mind-body interventions to reduce risk for health disparities related to stress and strength among African American women: the potential of mindfulness-based stress reduction, loving-kindness, and the NTU therapeutic framework. Complement Health Pract Rev. 2010;15(3):115-131.

29. Almehed K, Carlsten H, Forsblad-d'Elia H. Health-related quality of life in systemic lupus erythematosus and its association with disease and work disability. Scand J Rheumatol. 2010;39(1):58-62.

30. Butterworth P, Leach LS, Pirkis J, Kelaher M. Poor mental health influences risk and duration of unemployment: a prospective study. Soc Psychiatry Psychiatr Epidemiol. 2012;47(6):1013-1021.

31. Julian LJ, Yelin E, Yazdany J, et al. Depression, medication adherence, and service utilization in systemic lupus erythematosus. Arthritis Rheum. 2009;61(2):240-246.

32. Alarcón GS, McGwin G Jr, Uribe A, et al. Systemic lupus erythematosus in a multiethnic lupus cohort (LUMINA). XVII. Predictors of self-reported health-related quality of life early in the disease course. Arthritis Rheum. 2004;51(3):465-474.

33. Boomsma MM, Bijl M, Stegeman CA, Kallenberg CG, Hoffman GS, Tervaert JW. Patient's perceptions of the effects of systemic lupus erythematosus on health, function, income, and interpersonal relationships: a comparison with Wegener's granulomatosis. Arthritis Rheum. 2002;47(2):196-201. 
34. Dobkin PL, Fortin PR, Joseph L, Esdaile JM, Danoff DS, Clarke AE. Psychosocial contributors to mental and physical health in patients with systemic lupus erythematosus. Arthritis Care Res. 1998;11(1):23-31.

35. Doria A, Rinaldi S, Ermani M, et al. Health-related quality of life in Italian patients with systemic lupus erythematosus. II. Role of clinical, immunological and psychological determinants. Rheumatology (Oxford). 2004;43(12):1580-1586.
36. Rinaldi S, Ghisi M, Iaccarino L, et al. Influence of coping skills on health-related quality of life in patients with systemic lupus erythematosus. Arthritis Rheum. 2006;55(3):427-433.

37. Pettersson S, Lövgren M, Eriksson LE, et al. An exploration of patient-reported symptoms in systemic lupus erythematosus and the relationship to health-related quality of life. Scand J Rheumatol. 2012;41(5):383-390.

\section{Publish your work in this journal}

Patient Preference and Adherence is an international, peer-reviewed, open access journal that focuses on the growing importance of patient preference and adherence throughout the therapeutic continuum. Patient satisfaction, acceptability, quality of life, compliance, persistence and their role in developing new therapeutic modalities and compounds to optimize clinical outcomes for existing disease states are major areas of interest for the journal. This journal has been accepted for indexing on PubMed Central. The manuscript management system is completely online and includes a very quick and fair peer-review system, which is all easy to use. Visit http://www dovepress.com/testimonials.php to read real quotes from published authors.

Submit your manuscript here: http://www.dovepress.com/patient-preference-and-adherence-journal 